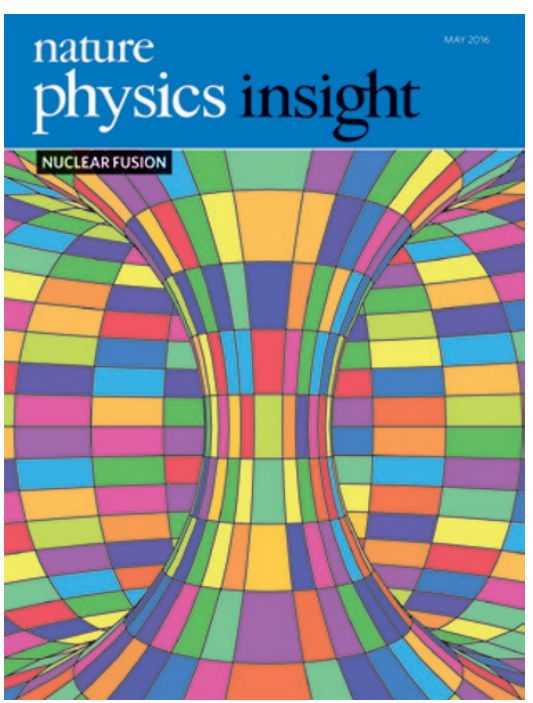

IMAGE: BART VERBERCK AND BETHANY VUKOMANOVIC

\section{NPG LONDON}

The Macmillan Building,

4 Crinan Street, London N1 9XW

T: +442078334000

F: +442078434563

naturephysics@nature.com

INSIGHTEDITOR

BART VERBERCK

CHIEF EDITOR

ANDREA TARONI

ART/PRODUCTION EDITOR ALLEN BEATTIE

SENIOR COPY EDITOR

KEVIN SHERIDAN

EDITORIAL ASSISTANT

RACHEL GROOCOCK

MARKETING MANAGER

SARAH-JANE BALDOCK

EXECUTIVE EDITOR

ALISON WRIGHT

EDITOR-IN-CHIEF,

NATURE PUBLICATIONS

PHILIP CAMPBELL

\section{Nuclear fusion}

ife on Earth would not be possible without the nuclear fusion reactions that power the Sun. By replicating even a fraction of this power on Earth, an almost limitless and clean supply of energy could be achieved - a true triumph for physics, engineering and society.

This Insight highlights the achievements that have been made and challenges that must be overcome if nuclear fusion is to become a reality. As Mark Buchanan points out in this month's Thesis, almost everything in the Universe is a plasma, and the key to taming them lies in dealing with their instabilities. This is but one of the many challenges faced by ITER, the long-awaited international tokamak now under construction. An interview with its Director-General, Bernard Bigot, highlights the goals and trials that lie ahead for the ITER organization.

In a series of Commentaries, Steven Cowley explains where we are in our quest for fusion energy, Alexander Melnikov reminds us that, in spite of its applied character, fusion research harbours some compelling fundamental physics, and Rob Buckingham and Antony Loving illustrate how remotehandling technology will be deployed in the

Four Review Articles get down to the nitty-gritty of fusion physics. These span everything from the principles of magneticconfinement fusion investigated in tokamaks and stellarators, to the fundamentals of inertial-confinement fusion approaches, as well as surveying the advances that have been made through computer simulations and the challenges that must be met in materials science if plasmas are to be contained.

Although our compilation is intended to be both broad in scope and rich in detail, we've unavoidably had to be selective - it is by no means exhaustive. Nevertheless, we hope that it conveys the excitement surrounding fusion plasma physics. The journey towards fusion energy is without doubt one that is worth making.

Bart Verberck, Senior Editor Andrea Taroni, Chief Editor context of tokamaks and beyond

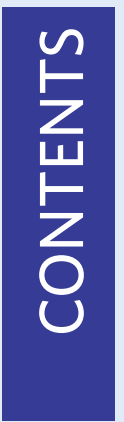

\section{COMMENTARY}

The quest for fusion power

Steven C. Cowley

Applied and fundamental aspects of fusion science

Alexander V. Melnikov

Remote-handling challenges in fusion research and beyond

Rob Buckingham and Antony Loving

THESIS

Everything is plasma

Mark Buchanan

INTERVIEW

Building the way to fusion energy

Interview with Bernard Bigot

REVIEW ARTICLES

Magnetic-confinement fusion

J. Ongena, R. Koch, R. Wolf and H. Zohm

Computational challenges in magnetic-confinement fusion physics

A. Fasoli, S. Brunner, W. A. Cooper, J. P. Graves, P. Ricci,

O. Sauter and L. Villard

Materials research for fusion

J. Knaster, A. Moeslang and T. Muroga

Inertial-confinement fusion with lasers

R. Betti and O. A. Hurricane 